Correction

\title{
Correction: Wasielewski, S., et al. Evaluation of Different Clinoptilolite Zeolites as Adsorbent for Ammonium Removal from Highly Concentrated Synthetic Wastewater. Water 2018, 10,584
}

\author{
Stephan Wasielewski ${ }^{1, *},{\text { Eduard } \text { Rott }^{1}}^{1}$, Ralf Minke ${ }^{1}$ and Heidrun Steinmetz ${ }^{2}$ (D) \\ 1 Institute for Sanitary Engineering, Water Quality and Solid Waste Management (ISWA), \\ University of Stuttgart, Bandtaele 2, 70569 Stuttgart, Germany; eduard.rott@iswa.uni-stuttgart.de (E.R.); \\ ralf.minke@iswa.uni-stuttgart.de (R.M.) \\ 2 Chair of Resource-Efficient Wastewater Technology, Faculty of Civil Engineering, University of \\ Kaiserslautern, Paul-Ehrlich-Str. 14, 67663 Kaiserslautern, Germany; heidrun.steinmetz@bauing.uni-kl.de \\ * Correspondence: stephan.wasielewski@iswa.uni-stuttgart.de; Tel.: +49-711-685-65425
}

check for updates

Citation: Wasielewski, S.; Rott, E.; Minke, R.; Steinmetz, H. Correction: Wasielewski, S., et al. Evaluation of Different Clinoptilolite Zeolites as Adsorbent for Ammonium Removal from Highly Concentrated Synthetic Wastewater. Water 2018, 10, 584. Water 2021, 13, 402. https://doi.org/ $10.3390 / w 13040402$

Received: 19 January 2021

Accepted: 27 January 2021

Published: 4 February 202

Publisher's Note: MDPI stays neutral with regard to jurisdictional claims in published maps and institutional affiliations.

Copyright: (c) 2021 by the authors. Licensee MDPI, Basel, Switzerland. This article is an open access article distributed under the terms and conditions of the Creative Commons Attribution (CC BY) license (https:// creativecommons.org/licenses/by/ $4.0 /)$.

\section{Error in Table}

In the original article [1], there was a mistake in Table 7 as published. An evaluation error was noted in the thermodynamic study section. The corrected Table 7 appears below. The authors apologize for any inconvenience caused and state that the scientific conclusions are unaffected. The original article has been updated.

Table 7. Thermodynamic properties of CCP 20, Micro 200, and EcoZeo 20 after $20 \mathrm{~h}$ contact time with ammonium solution ( $\mathrm{c}_{0}=1000 \mathrm{mg} \mathrm{NH}_{4}-\mathrm{N} / \mathrm{L}, \mathrm{pH}_{\text {Start }}$ 5.3, $\mathrm{pH}_{\text {End }}$ 6.5-7.3).

\begin{tabular}{ccccc}
\hline \multirow{2}{*}{ CLI } & Temperature & Free Reaction Enthalpy & Free Standard Enthalpy & \multicolumn{2}{c}{ Molar Standard Entropy } \\
\cline { 2 - 5 } & $\mathbf{T}$ & $\boldsymbol{\Delta} \mathbf{G}^{\mathbf{0}}$ & $\boldsymbol{\Delta} \mathbf{H}^{\mathbf{0}}$ & $\boldsymbol{\Delta} \mathbf{S}^{\mathbf{0}}$ \\
\cline { 2 - 5 } & {$[\mathbf{K}]$} & {$[\mathbf{k J} / \mathbf{m o l}]$} & {$[\mathbf{k J} / \mathbf{m o l}]$} & -6.8 \\
CCP 20 & 283 & -15.0 & -16.9 & 17.6 \\
& 295 & -15.0 & & \\
\hline \multirow{2}{*}{ Micro } & 307 & -14.8 & -9.1 & \\
200 & 283 & -13.9 & & 32.7 \\
\hline \multirow{2}{*}{ EcoZeo } & 307 & -14.3 & -4.7 & \\
20 & 283 & -14.2 & & \\
\hline
\end{tabular}

\section{Text Correction}

There was an error in the original article. A correction has been made to the following lines. Page 1, line 24: The process was "exothermic".

Page 5, line 24: A bracket was omitted in Equation (4). This should be corrected as follows:

$$
\mathrm{q}_{\mathrm{eq}}=\frac{\left(\mathrm{c}_{0}-\left(\mathrm{c}_{0}-\mathrm{c}_{\mathrm{B}}\right)-\mathrm{c}_{\mathrm{eq}}\right) \times\left(\frac{\mathrm{V}_{\mathrm{p}}}{1000}\right)}{\mathrm{m}}
$$

Page 12, lines 11-14: Due to the changed values of the thermodynamic study, the interpretation in the text must be adjusted as follows:

"The free standard enthalpy $\Delta \mathrm{H}_{0}$ of all three sorbents was negative, indicating an exothermic reaction. The standard molar entropy $\Delta S_{0}$, which was positive for Micro 200 and EcoZeo 20, indicates that the ammonium adsorption is a directional process, decreasing 
slightly as the temperature increases. However, the negative molar standard entropy of CCP 20 indicates that the sorption process was random."

Page 12, line 23-25 and page 13, lines 1-5: Due to the changed values of the thermodynamic study, the interpretation in the text must be adjusted as follows:

"Similar to the results published by other researchers $\left(\Delta \mathrm{H}^{0}:-49.384,-22.34,-5.43\right.$, $-15.38 \mathrm{~kJ} / \mathrm{mol}[14,19,45,46])$, which indicate that adsorption of ammonium is exothermic, a slightly exothermic adsorption was found for the CLIs tested in this study ( $\triangle \mathrm{H} 0$ ranging from -4.7 (EcoZeo 20) to $-16.9 \mathrm{~kJ} / \mathrm{mol}$ (CCP 20)). Furthermore, results reported with negative values of $\Delta \mathrm{SO}(-156.1,-74.42,-43.03,-49.34, \mathrm{~J} /(\mathrm{K} \mathrm{mol})[14,19,45,46])$ indicate decreasing ammonium uptake due to increasing randomness. In contrast to this, a strongly directed adsorption process, as indicated by positive $\Delta S^{0}$ values ranging between 32.7 (EcoZeo 20) and $17.6 \mathrm{~J} /(\mathrm{K} \mathrm{mol})$ (Micro 200), was achieved with the investigated materials of this study."

Page 14, line 29: The adsorption process observed was "exothermic".

The authors apologize for any inconvenience caused and state that the scientific conclusions are unaffected. The original article has been updated.

\section{Reference}

1. Wasielewski, S.; Rott, E.; Minke, R.; Steinmetz, H. Evaluation of Different Clinoptilolite Zeolites as Adsorbent for Ammonium Removal from Highly Concentrated Synthetic Wastewater. Water 2018, 10, 584. [CrossRef] 